\title{
Adhesion of Pseudomonas aeruginosa to silicone rubber in a parallel plate flow chamber in the absence and presence of nutrient broth
}

\author{
Marc B. Habash, ${ }^{1}$ Henny C. van der Mei, $^{2}$ Gregor Reid ${ }^{1,3}$ \\ and Henk J. Busscher ${ }^{1,2}$ \\ Author for correspondence: Henk J. Busscher. Tel: +31363 3140. Fax : +313633159 \\ e-mail: H.J.Busscher@med.rug.nl.
}

1 Department of
Microbiology and
Immunology, University of
Western Ontario Health
Sciences Centre, London,
Ontario, Canada N6A 5C1
2 Materia Technica,
University of Groningen,
Bloemsingel 10, 9712 KZ
Groningen, The
Netherlands
3 Lawson Research Institute,
London, Ontario
Canada N6A 4V2

\begin{abstract}
The physico-chemical cell-surface properties of Pseudomonas aeruginosa AK1 and its adhesion to silicone rubber under flow were compared for cells suspended in phosphate-buffered saline (PBS) or PBS supplemented with $2 \%$ nutrient broth. Addition of $2 \%$ nutrient broth to cells suspended in PBS yielded minimal growth and did not significantly change the mean zeta potential of the organisms, which was around $-13 \mathrm{mV}$. However, a comparatively larger proportion of the organisms had more negative zeta potentials in the presence of nutrient broth. This change was concurrent with a slight decrease in cellsurface hydrophobicity, as measured by water contact angles, from $119^{\circ}$ to around $112^{\circ}$. The initial deposition rate of $P$. aeruginosa AK1 to silicone rubber, as studied in a parallel plate flow chamber, increased from $344 \mathrm{~cm}^{-2} \mathrm{~s}^{-1}$ in the absence of nutrient broth to $505 \mathrm{~cm}^{-2} \mathrm{~s}^{-1}$ in its presence. No stationary level of adhesion was observed in the presence of nutrient broth, instead the number of adhering cells increased steadily at a rate of approximately $85 \mathrm{~cm}^{-2} \mathrm{~s}^{-1}$. Fluorescent staining of adhering cells demonstrated that for adhesion from buffer only $2 \%$ of the adhering cells were metabolically active, whereas in case of deposition from PBS supplemented with nutrient broth, $67 \%$ of the adhering cells were metabolically active. It is concluded that the deposition rates measured in the parallel plate flow chamber with $2 \%$ nutrient broth added to the PBS suspension represent an interplay of adhesion and surfaceassociated growth.
\end{abstract}

Keywords: silicone rubber, Pseudomonas aeruginosa, adhesion, growth, parallel plate flow chamber

\section{INTRODUCTION}

A wide variety of biomedical implants ranging from mammary and larynx prostheses to urinary and intravenous catheters are comprised of silicone rubber (Gristina et al., 1988). However, common to nearly all biomedical implants is the adhesion of infectious microorganisms that may ultimately lead to removal of the implant. Silicone rubber is especially prone to becoming colonized with Candida, staphylococci, streptococci or Pseudomonas species depending on the site of implantation (Gristina et al., 1988; Salzman \& Rubin, 1995). The development of an infectious biofilm is initiated by the adhesion of bacteria to the implant

Abbreviation: CTC, 5-cyano-2,3-ditolyl tetrazolium chloride. surface. The initial colonizing organisms are of importance as they play a pivotal role in the linking of the final biofilm to the implant surface (Busscher et al., 1995).

Initial microbial adhesion to surfaces is generally considered to be an interplay of various physico-chemical properties of the interacting surfaces (i.e. the implant and the microbial cell surfaces), most notably their hydrophobicity and charge (Busscher \& Weerkamp, 1987; Van Loosdrecht et al., 1987a, b). Physico-chemical studies on microbial adhesion to surfaces are typically carried out with organisms suspended in buffers to avoid microbial growth or other associated complications (Van Loosdrecht et al., 1990). In vitro studies have identified changes in antimicrobial efficacy (Evans $e t$ al., 1990, 1991), protein expression (Harakeh \& Matin, 
1989), cell-surface hydrophobicity (Ljungh \& Wadström, 1995) and adhesion (Fletcher, 1976; Zeng et al., 1994), depending upon growth conditions. Alternatively, adhesion studies sometimes involve optimal growth conditions. Recently, Barton et al. (1996a) compared adhesion of Staphylococcus epidermidis, Pseudomonas aeruginosa and Escherichia coli to orthopaedic implant polymers for organisms suspended in phosphate-buffered saline (PBS), tryptic soy broth and hyaluronic acid. They found that adhesion in whole broth was decreased compared to adhesion in buffer, while the presence of hyaluronic acid increased bacterial adhesion.

Although there is a consensus that the metabolic activity of bacteria adhering to surfaces in natural environments under nutrient availability is influenced by the presence of a surface, experimental observations are not consistent. In a review, Van Loosdrecht et al. (1990) summarized studies reporting increased as well as decreased growth rates of bacteria on surfaces as compared to planktonic bacteria, while increased adhesion of metabolically active cells was also found. The mechanisms of surface-associated changes in bacterial behaviour are probably related to nutrient accumulation at the surface and thus are related to the physicochemical properties of the substratum surface, including charge and hydrophobicity, and the physico-chemical nature of the nutrients themselves. The nutrient conditions around a biomaterials implant are extremely complex and possibly vary over time. Thus it is doubtful whether carrying out adhesion experiments with bacteria suspended either in buffers or under optimal laboratory growth conditions as in whole broth, represent clinically relevant conditions.

We have compared, in a parallel plate flow chamber, the adhesion to silicone rubber of a $P$. aeruginosa strain suspended in PBS or PBS supplemented with a minimal amount of nutrient broth. The metabolic activity of the adhering bacteria was determined under both nutrient conditions by utilizing a viable fluorescent stain (5cyano-2,3-ditolyl tetrazolium chloride; CTC). Furthermore, the effects of supplementing the PBS with a minimal amount of nutrient broth upon the microbial zeta potentials and intrinsic cell surface hydrophobicities (by water contact angles) were measured.

\section{METHODS}

Strain and growth conditions. Pseudomonas aeruginosa AK1, a uropathogenic isolate, was used in this study. The strain was streaked and grown overnight at $37^{\circ} \mathrm{C}$ from a frozen stock on a nutrient agar plate (Oxoid). The plate was then kept at $4{ }^{\circ} \mathrm{C}$ for not more than one week, at which time a new plate was streaked. Several colonies were used to inoculate a 'preculture' that was incubated at $37^{\circ} \mathrm{C}$ in ambient air for $24 \mathrm{~h}$. The 'preculture' was utilized to inoculate a second culture that was grown for $16 \mathrm{~h}$. The bacteria from the second culture were harvested by centrifugation at $5000 \mathrm{~g}$ for $5 \mathrm{~min}$ at $10^{\circ} \mathrm{C}$ and washed twice with Millipore- $Q$ water. Subsequently, the bacteria were sonicated on ice three times for $10 \mathrm{~s}$ and then resuspended at a concentration of $3 \times 10^{8}$ cells $\mathrm{ml}^{-1}$ in either sterile PBS (10 mM potassium phosphate and $150 \mathrm{mM}$ sodium chloride, $\mathrm{pH} 7.0$ ) or PBS supplemented with nutrient broth.

To determine the concentration of nutrient broth constituting minimal growth conditions, growth curves were made over a $24 \mathrm{~h}$ time interval for cells suspended in PBS (control), in PBS supplemented with various concentrations of nutrient broth (varying from $0.5 \%$ to $10 \%$ ) and in whole nutrient broth (optimal growth condition). Optical densities of the suspensions were measured with a Spectronic 20 (Bausch $\&$ Lomb) at $600 \mathrm{~nm}$.

Silicone rubber. A silastic medical grade silicone rubber kit (Q7-4750, Nusil) was purchased and plates were produced following the procedures suggested by the manufacturer. Briefly, equal proportions of part A and part B were thoroughly blended together and injected into a mould at room temperature through a $3 \mathrm{~mm}$ diam. opening with a force of 3 tons. The silicone rubber was immediately cured at $200^{\circ} \mathrm{C}$ for 50 min. Finally, samples were cleaned in a $2 \%$ RBS detergent solution under simultaneous sonication and thoroughly rinsed in demineralized water, methanol, again with demineralized water and lastly with Millipore- $Q$ water.

Microbial cell-surface characterization. The Pseudomonas cells used in this study were characterized by their zeta potentials and surface hydrophobicity, as possible determinants for their adhesive cell-surface properties.

For zeta potential measurements (Hiemenz, 1977), three independently grown cultures were harvested and washed as described above. The collected cells were resuspended $\left(3 \times 10^{7}\right.$ cells ml $\left.^{-1}\right)$ in either sterile PBS (pH 7.0) or sterile PBS supplemented with $2 \%$ nutrient broth and kept at room temperature for up to $4 \mathrm{~h}$, a time interval comparable with the duration of the adhesion experiments in the parallel plate flow chamber. Zeta potentials were measured either directly after resuspending the cells or after $4 \mathrm{~h}$ exposure of the bacteria to PBS or minimal growth conditions, i.e. PBS supplemented with $2 \%$ nutrient broth. The electrophoretic mobility of each sample was measured at $150 \mathrm{~V}$ using a Lazer Zee Meter 501 (PenKem) and converted into zeta potentials assuming that the Helmholtz-Smoluchowski equation holds. An automated version of the Lazer Zee Meter was employed (Noordmans et al., 1993) allowing the determination of the zeta potential distribution of individual cells.

The contact angle measurements on $P$. aeruginosa AK1 lawns, of three individual cultures, were done as previously described using the sessile drop technique (van der Mei et al., 1987) as a measure of the intrinsic cell surface hydrophobicity. Briefly, $P$. aeruginosa AK1 was kept either in water (as for standard contact angle measurements on microbial lawns), sterile PBS or PBS supplemented with $2 \%$ nutrient broth for up to $4 \mathrm{~h}$ at room temperature. Subsequently, bacteria were harvested, washed, resuspended in Millipore- $Q$ water and deposited on $0.45 \mu \mathrm{m}$ pore-size cellulose acetate filters to produce a lawn of approximately 50 stacked layers. The $P$. aeruginosa AK1 lawns were air-dried until so-called 'plateau contact angles' (Van Oss \& Gillman, 1972) could be measured with water, followed by contact angle measurements with formamide, methylene iodide and $\alpha$-bromonaphthalene.

The parallel flow plate chamber, image analysis and adhesion assay. The flow chamber (dimensions, $1 \times \mathrm{w} \times \mathrm{h}=$ $76 \times 38 \times 0.6 \mathrm{~mm})$ and image analysis system have been described in detail by Busscher \& van der Mei (1995). Images were taken from the bottom plate $(58 \times 38 \mathrm{~mm})$ of the parallel plate flow chamber which consisted of a thin square $(15 \times 15 \times 0.5 \mathrm{~mm})$ of silicone rubber affixed centrally into the 
groove $(58 \times 15 \times 0.5 \mathrm{~mm})$ of the thicker $(2.0 \mathrm{~mm})$ perspex plate. The top plate of the chamber was made of glass. Deposition was observed with a CCD-MXRi camera (High Technology) mounted on a combined fluorescent/phase contrast microscope (Olympus BH-2) equipped with a $40 \times$ ultra long working distance objective (Olympus ULWD-CD Plan $40 \mathrm{PL}$ ). The camera was coupled to an image analyser (TEA, Difa).

Prior to each experiment, all tubes and the flow chamber were filled with either PBS or PBS with $2 \%$ nutrient broth added, taking care to ensure that all air bubbles were removed from the system. Once the system was filled, and prior to the addition of the bacterial suspension, the fluid was allowed to flow through the system at a flow rate of $0.025 \mathrm{ml} \mathrm{s}^{-1}$ corresponding with a shear rate of $10 \mathrm{~s}^{-1}$ for $10 \mathrm{~min}$ and subsequently switched to the appropriate bacterial suspension at the same flow rate. The bacterial suspension was perfused through the system for $4 \mathrm{~h}$ without recirculation and images were obtained in the phase contrast mode of the microscope system at predetermined time points. The increase in the number of adhering bacteria over time, both initially as well as in a more advanced state of the adhesion process was expressed in so-called deposition rates, i.e. the increase in the number of adhering bacteria per unit area and time.

Following $4 \mathrm{~h}$ perfusion of the flow chamber with bacterial suspension, flow was switched to buffer without bacteria to remove unbound organisms from the tubes and the flow chamber under the same flow rate and $3 \mathrm{ml}$ of the fluorescent viable cell stain CTC (5 mM) was added without introducing any air bubbles or additional shear. The flow chamber was then incubated in the dark at $37^{\circ} \mathrm{C}$ for $2 \mathrm{~h}$. CTC, a tetrazolium stain, fluoresces when taken up and reduced by the electron transport chain of metabolically active bacterial cells (Rodriguezs et al., 1992). The stain can then be observed as red fluorescent crystals within the bacteria at an emission maximum of $602 \mathrm{~nm}$. The number of adherent, metabolically active cells were counted at 12 separate locations on the silicone rubber surface utilizing the fluorescent mode of the microscope, while the phase contrast mode of the microscope was used to enumerate the total number of adhering bacteria at the same locations.

\section{RESULTS}

Fig. 1 shows the growth curves of $P$. aeruginosa AK1 cells suspended in PBS supplemented with various amounts of nutrient broth. As can be seen, growth is virtually absent when less than $2 \%$ broth is added, while for higher concentrations of broth significant growth occurs. Therefore, minimal growth conditions in the remainder of this paper will refer to PBS with $2 \%$ nutrient broth added.

Fig. 2 shows the zeta potential distributions of $P$. aeruginosa $\mathrm{AK} 1$ under the various conditions relevant to this study. The zeta potential distribution of freshly cultured cells in buffer (Fig. 2a) is relatively narrow (sD $5 \mathrm{mV}$ over 1015 cells) with a mean zeta potential of $-13 \mathrm{mV}$. After prolonged exposure to buffer (Fig. 2b), however, zeta potentials tended to become more negative $(-17 \mathrm{mV})$, with a higher SD of $11 \mathrm{mV}$ over a population of 399 cells. Exposure of cells to minimal growth conditions (Fig. 2c) also yielded the appearance of greater numbers of more negatively charged cells,

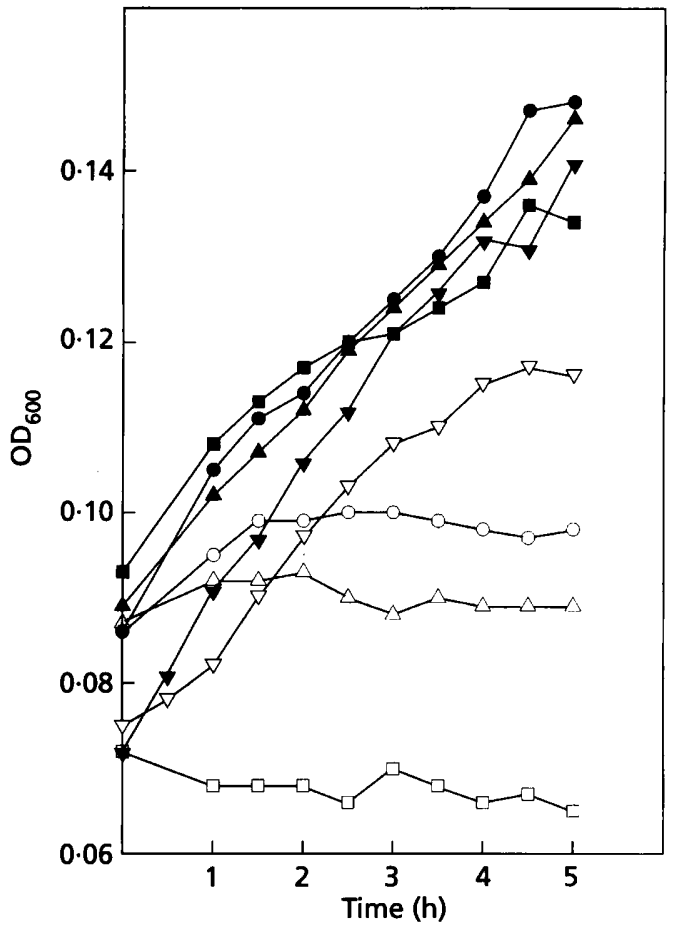

Fig. 1. Growth of Pseudomonas aeruginosa AK1 suspensions with various concentrations of nutrient broth added: $\square, 0 \%$; $\triangle, 0.5 \% ; 0,1.0 \% ; \nabla, 2.0 \% ; \square, 2.5 \% ; \Delta, 5.0 \% ; 0,10.0 \% ; \nabla$, $100.0 \%$.

though the mean zeta potential of the bacterial population as a whole remained around $-19 \pm 11 \mathrm{mV}$ (SD over 170 cells) prior to washing. Also after washing (Fig. $2 \mathrm{~d})$ a relatively wide zeta potential distribution of $-16 \pm 9 \mathrm{mV}$ (SD over 278 cells) was observed.

Contact angles, summarized in Table 1 , indicate that $P$. aeruginosa $\mathrm{AK} 1$ is a hydrophobic organism with a water contact angle of around $106^{\circ}$, when measured routinely. Both exposure to PBS as well as exposure to PBS supplemented with $2 \%$ nutrient broth for $4 \mathrm{~h}$ yielded a slight increase in the intrinsic cell surface hydrophobicity as shown by water contact angles, a trend which was also reflected in the formamide contact angles. The contact angles measured with methylene iodide and $\alpha$ bromonaphthalene, probing apolar cell surface properties, were not appreciably influenced. However, exposure of bacteria to PBS supplemented with $2 \%$ nutrient broth gave a slight decrease in water contact angles from $119^{\circ}$ in $\mathrm{PBS}$ to $112^{\circ}$.

Fig. 3 shows the numbers of $P$. aeruginosa cells adhering to silicone rubber under both nutrient conditions. Interestingly, when the organisms were suspended in buffer a stationary level of adhesion was obtained within $60 \mathrm{~min}$ with an initial deposition rate of $344 \pm 83$ $\mathrm{cm}^{-2} \mathrm{~s}^{-1}$ (SD over three separate experiments), while fluorescent microscopy indicated that only $2 \%$ of the adhering organisms were metabolically active. Under minimal growth conditions, the initial deposition rate 


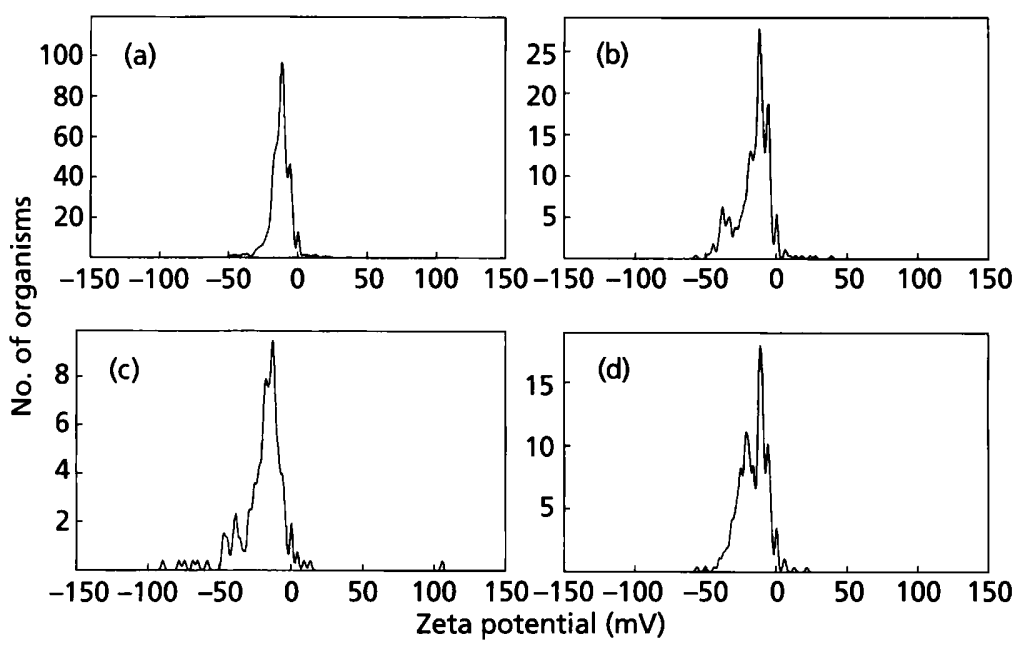

Fig. 2. Zeta potential $(\mathrm{mV})$ distributions of Pseudomonas aeruginosa AK1 under various conditions. (a) Bacteria transferred to PBS (pH 7.0) immediately after harvesting $(n=$ 1015 cells); (b) bacteria transferred to PBS (pH 7.0) immediately after harvesting and left for $4 \mathrm{~h}$ prior to measurement $(n=399$ cells); (c) bacteria transferred to PBS ( $\mathrm{pH} 7.0$ ) supplemented with $2 \%$ nutrient broth and left for $4 \mathrm{~h}$ prior to measurement $(n=170$ cells); (d) bacteria transferred to PBS ( $\mathrm{pH} 7.0$ ) supplemented with $2 \%$ nutrient broth, left for $4 \mathrm{~h}$, washed and resuspended in PBS prior to measurement $(n=278$ cells).

Table 1. Contact angles of water, formamide, methylene iodide and $\alpha$-bromonaphthalene on $P$. aeruginosa AK1

The bacteria were kept in either PBS or PBS supplemented with $2 \%$ nutrient broth (PBS + ) at $25^{\circ} \mathrm{C}$ for up to $4 \mathrm{~h}$, then washed in Millipore-Q water and collected on cellulose acetate filters $(0.45 \mu \mathrm{m})$.

These results are based on contact angles measured for three separate cultures of $P$. aeruginosa AK1 \pm SD.

\begin{tabular}{|clcccc|}
\hline $\begin{array}{c}\text { Time } \\
\text { (h) }\end{array}$ & Medium & Water & Formamide & $\begin{array}{c}\text { Methylene } \\
\text { iodide }\end{array}$ & $\boldsymbol{\alpha}$-Bromonaphthalene \\
\hline 0 & Water* & $106 \pm 7$ & $52 \pm 3$ & $52 \pm 3$ & $39 \pm 5$ \\
4 & PBS & $119 \pm 3$ & $65 \pm 2$ & $52 \pm 2$ & $41 \pm 1$ \\
& PBS + & $112 \pm 6$ & $60 \pm 4$ & $50 \pm 5$ & $36 \pm 4$ \\
\hline
\end{tabular}

* Standard contact angle measurement on microbial lawns according to van der Mei et al. (1987).

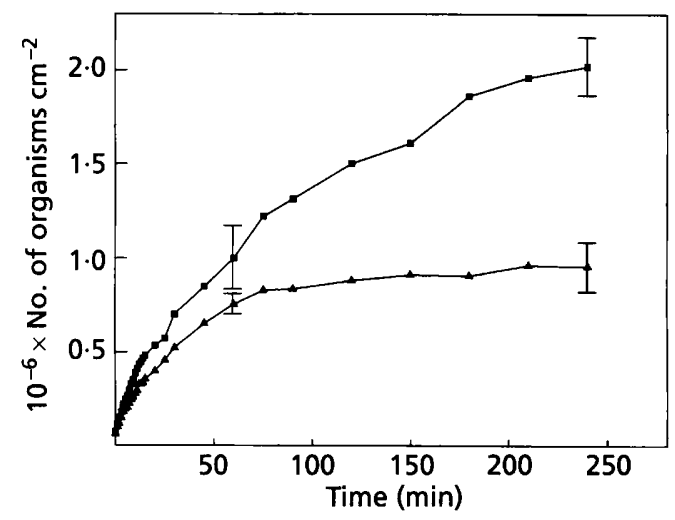

Fig. 3. The numbers of $P$. aeruginosa AK1 cells adhering to silicone rubber in a parallel plate flow chamber as a function of time when suspended in PBS $(\boldsymbol{A})$ or in PBS supplemented with $2 \%$ nutrient broth $(\boldsymbol{D})$. Bars represent the SD over three experiments with separate bacterial cultures.

was slightly higher $\left(505 \pm 79 \mathrm{~cm}^{-2} \mathrm{~s}^{-1}\right)$ while no stationary level of adhesion was obtained. Instead, the number of adhering micro-organisms steadily increased, even after $200 \mathrm{~min}$, at a rate of approximately
$85 \pm 31 \mathrm{~cm}^{-2} \mathrm{~s}^{-1}$. However, the percentage of metabolically active cells under minimal growth conditions was much higher than in PBS and amounted to $67 \%$.

\section{DISCUSSION}

In this work adhesion of $P$. aeruginosa AK1 to silicone rubber was studied in a parallel plate flow chamber, with both metabolically active and inactive bacteria. The conditions chosen to stimulate metabolic activity of the bacteria were such that minimal growth of bacteria in suspension occurred. The deposition kinetics observed in this study demonstrate that the number of bacteria adhering to the silicone rubber from PBS supplemented with $2 \%$ nutrient broth did not reach stationary numbers in contrast to bacteria suspended in PBS. Instead, even after $3 \mathrm{~h}$, the number of bacteria on the silicone rubber increased at a rate of $85 \mathrm{~cm}^{-2} \mathrm{~s}^{-1}$ in PBS supplemented with $2 \%$ nutrient broth. Considering that neither the zeta potentials nor the cell surface hydrophobicities of the majority of metabolically active bacteria change in a direction anticipated to be accompanied by increased adhesion (Van Loosdrecht, $1987 \mathrm{a}, \mathrm{b})$, we attribute this increase to surface-associated growth (Van Loosdrecht, 1990). We do not believe 
that the presence of only $2 \%$ nutrient broth in suspension stimulates significant growth of planktonic bacteria, but accumulated nutrients may be available at the silicone rubber surface in sufficient concentration to yield significant growth of adhering bacteria (Pringle \& Fletcher, 1986; Hawthron \& Reid, 1990; Reid et al., 1994; Marshall, 1985).

The deposition kinetics of metabolically inactive bacteria in a parallel plate flow chamber are governed by convective-diffusion and desorption (Sjollema et al., 1989). Although bacterial desorption is measurable (Meinders et al., 1994), desorption rates are usually small and in the order of $10^{-6} \mathrm{~s}^{-1}$, which is negligible compared to the adsorption rate. The difference in initial deposition rates between bacteria suspended in PBS and in PBS supplemented with nutrient broth may be associated with a growth component (Bryers \& Characklis, 1992). The difference in initial deposition rates under the two nutrient conditions amounts to $171 \mathrm{~cm}^{-2} \mathrm{~s}^{-1}$, of which $67 \%$ appeared as metabolically active bacteria by CTC staining. Consequently, it can be calculated that growth will contribute to the number of adhering bacteria at a rate of $114 \mathrm{~cm}^{-2} \mathrm{~s}^{-1}$, which corresponds well, within experimental reproducibility, with the increase in the number of adhering bacteria after $3 \mathrm{~h}$, i.e. $85 \mathrm{~cm}^{-2} \mathrm{~s}^{-1}$ and thus constitutes a quantitative confirmation of the hypotheses on surface accumulation of bacteria by deposition and surfaceassociated growth (Van Loosdrecht $e t$ al., 1990). Barton et al. (1996b) compared the growth rates of $S$. epidermidis, $P$. aeruginosa and $E$. coli in their planktonic state when suspended in tryptic soy broth and when adhering to various polymers. Generation times of planktonic bacteria were shorter than those of adhering bacteria. For adhering $P$. aeruginosa, generation times between 37 and $51 \mathrm{~min}$ were reported, depending on the substratum surface. From our present results, it can be estimated that under minimal growth conditions on silicone rubber, the generation time of $P$. aeruginosa AK1 amounts to $136 \mathrm{~min}$, which is about threefold longer than the generation times reported by Barton et al. (1996b) for optimal growth conditions.

Physico-chemical cell-surface characteristics of more metabolically active bacteria were on average identical to those of inactive bacteria, although the water contact angles indicate a minor decrease in intrinsic cell surface hydrophobicity (see Table 1). Unfortunately, water contact angles do not give information on individual bacteria. Particulate microelectrophoresis is capable of providing zeta potentials of individual bacteria and showed that a population of metabolically more active bacteria contains a larger proportion of more negatively charged bacteria than a suspension of metabolically inactive bacteria. These observations suggest that metabolically active cells change their cell surface properties during their division cycle. Whereas the cell surface hydrophobicity changed only slightly, newly formed cells had significantly more negative zeta potentials. Earlier, Gilbert et al. (1991) also found that the growth phase of E. coli and S. epidermidis affected the electro- phoretic mobility of these bacteria. E. coli was shown to be less negatively charged in its lag phase than in its early exponential growth phase (Allison et al., 1990b), S. epidermidis showed a decrease in negative surface charge towards neutrality with progression of the growth phase into mid-exponential phase and restoration of the negative charge after entry into the stationary phase. Our present results on the intrinsic hydrophobicity of $P$. aeruginosa under growth confirm the conclusion by Allison et al. (1990a) that newly formed daughter cells of this organism are more hydrophilic.

In summary, this paper demonstrates that quantitative data on adhesion and surface-associated growth of $P$. aeruginosa can be interpreted to yield the separate contributions of deposition by convective-diffusion and of growth. Analysis of bacterial deposition data obtained in the parallel plate flow chamber under minimal growth conditions is more complicated than in the absence of nutrients in suspension, but is more relevant to the events occurring in natural environments without impeding a physico-chemical approach.

\section{REFERENCES}

Allison, D. G., Brown, M. R., Evans, D. J. \& Gilbert, P. (1990a). Surface hydrophobicity and dispersal of Pseudomonas aeruginosa from biofilms. FEMS Microbiol Lett 59, 101-104.

Allison, D. G., Evans, D. J., Brown, M. R. W. \& Gilbert, P. (1990b). Possible involvement of the division cycle in dispersal of Escherichia coli from biofilms. J Bacteriol 172, 1667-1669.

Barton, A. J., Sagers, R. D. \& Pitt, W. G. (1996a). Bacterial adhesion to orthopedic implant polymers. J Biomed Mater Res 30, 403-410.

Barton, A. J., Sagers, R. D. \& Pitt, W. G. (1996b). Measurement of bacterial growth rates on polymers. J Biomed Mater Res 32, 271-278.

Bryers, J. D. \& Characklis, W. G. (1992). Biofilm accumulation and activity: a process analysis approach. NATO ASI Ser Ser E Appl Sci 223, 221-238.

Busscher, H. J. \& van der Mei, H. C. (1995). Use of flow chamber devices and image analysis methods to study microbial adhesion. Methods Enzymol 253, 455-477.

Busscher, H. J. \& Weerkamp, A. H. (1987). Specific and nonspecific interactions in bacterial adhesion to solid substrata. FEMS Microbiol Rev 46, 146-173.

Busscher, H. J., Bos, R. \& van der Mei, H. C. (1995). Initial microbial adhesion is a determinant for the strength of biofilm adhesion. FEMS Microbiol Lett 128, 229-234.

Evans, D. J., Allison, D. G., Brown, M. R. W. \& Gilbert, P. (1990). Effect of growth-rate on resistance of Gram-negative biofilms to cetrimide. J Antimicrob Chemother 26, 473-478.

Evans, D. J., Allison, D. G., Brown, M. R. W. \& Gilbert, P. (1991). Susceptibility of Pseudomonas aeruginosa and Escherichia coli biofilms towards ciprofloxacin: effect of specific growth rate. $J$ Antimicrob Chemother 27, 177-184.

Fletcher, M. (1976). The effects of culture and age, time, and temperature on bacterial attachment to polystyrene. Can J Microbiol 23, 1-6.

Gilbert, P., Evans, D. J., Duguid, I. G., Evans, E. \& Brown, M. R. W. (1991). Cell surface properties of Escherichia coli and Staphylococcus epidermidis. In Microbial Cell Surface Analysis - Struc- 
tural and Physico-Chemical Methods, pp. 339-356. Edited by N. Mozes, P. S. Handley, H. J. Busscher \& P. G. Rouxhet. New York: VCH Publishers.

Gristina, A. G., Naylor, P. \& Myrvik, Q. (1988). Infections from biomaterials and implants: a race for the surface. Med Prog Technol 14, 205-224.

Harakeh, S. \& Matin, A. (1989). Influence of nutrient-limited growth on pathogenesis-associated outer membrane proteins of Yersinia enterocolitica. J Appl Bacteriol 67, 209-212.

Hawthorn, L. \& Reid, G. (1990). The effect of protein and urine on uropathogen adhesion to polymer substrata.J Biomed Mater Res 24, 1325-1332.

Hiemenz, P. C. (1977). Electrophoresis and other electrokinetic phenomena. In Principles of Colloid and Surface Chemistry, pp. 452-487. Edited by J. J. Lagowski. New York \& Basel: Marcel Dekker.

Ljungh, Å. \& Wadström, T. (1995). Growth conditions influence expression of cell surface hydrophobicity of staphylococci and other wound infection pathogens. Microbiol Immunol 39, 753-757.

Marshall, K. C. (1985). Mechanisms of bacterial adhesion at solid-water interfaces. In Bacterial Adhesion: Mechanisms and Physiological Significance, pp. 133-161. Edited by D. C. Savage \& M. Fletcher. New York: Plenum Press.

van der Mei, H. C., Weerkamp, A. H. \& Busscher, H. J. (1987). A comparison of methods to determine hydrophobic properties of streptococcal cell surfaces. J Microbiol Methods 6, 277-287.

Meinders, J., van der Mei, H. C. \& Busscher, H. J. (1994). Physicochemical aspects of deposition of Streptococcus thermophilus B to hydrophobic and hydrophilic substrata in a parallel plate flow chamber. J Colloid Interface Sci 164, 355-363.

Noordmans, J., Kempen, J. \& Busscher, H. J. (1993). Automated image analysis to determine zeta potential distributions in particulate microelectrophoresis. J Colloid Interface Sci 156, 394-399.
Pringle, J. H. \& Fletcher, M. (1986). Influence of substratum hydration and adsorbed macromolecules on bacterial attachment to surfaces. Appl Environ Microbiol 51, 1321-1325.

Reid, G., Khoury, A. E., Preston, C. A. K. \& Costeron, J. W. (1994). Influence of dextrose dialysis solutions on adhesion of Staphylococcus aureus and Pseudomonas aeruginosa to three catheter surfaces. Am J Nephrol 14, 37-40.

Rodriguezs, G. G., Phipps, D., Ishiguro, K. \& Ridgway, H. F. (1992). Use of a fluorescent redox probe for direct visualization of actively respiring bacteria. Appl Environ Microbiol 58, 1801-1808.

Salzman, M. B. \& Rubin, L. G. (1995). Intravenous catheter-related infections. Adv Pediatr Infect Dis 10, 337-368.

Sjollema, J., Busscher, H. J. \& Weerkamp, A. H. (1989). Experimental approaches for studying adhesion of microorganisms to solid substrata: applications and mass transport. J Microbiol Methods 9, 73-78.

Van Loosdrecht, M. C. M., Lyklema, J., Norde, W., Schraa, G. \& Zehnder, A. J. B. (1987a). The role of bacterial cell wall hydrophobicity in adhesion. Appl Environ Microbiol 53, 1893-1897.

Van Loosdrecht, M. C. M., Lyklema, J., Norde, W., Schraa, G. \& Zehnder, A. J. B. (1987b). Electrophoretic mobility and hydrophobicity as a measure to predict the initial steps of bacterial adhesion. Appl Environ Microbiol 53, 1898-1901.

Van Loosdrecht, M. C. M., Lyklema, J., Norde, W. \& Zehnder, A. J. B. (1990). Influence of interfaces on microbial activity. Microbiol Rev 54, 75-87.

Van Oss, C. J. \& Gillman, C. F. (1972). Phagocytosis as a surface phenomenon. I. Contact angles and phagocytosis of nonopsonized bacteria. J Reticuloendothel Soc 12, 283-292.

Zheng, D., Taylor, G. T. \& Gyananath, G. (1994). Influence of laminar flow velocity and nutrient concentration on attachment of marine bacterioplankton. Biofouling 8, 107-120.

Received 20 January 1997; revised 21 March 1997; accepted 3 April 1997. 